\title{
Genetic stability of Brucella abortus isolates from an outbreak by multiple-locus variable-number tandem repeat analysis (MLVA16)
}

\author{
Elaine Maria Seles Dorneles ${ }^{1}$, Jordana Almeida Santana ${ }^{1}$, Telma Maria Alves ${ }^{1}$, Rebeca Barbosa Pauletti ${ }^{1}$, \\ Juliana Pinto da Silva Mol ${ }^{1}$, Marcos Bryan Heinemann ${ }^{1,2}$ and Andrey Pereira Lage ${ }^{1 *}$
}

\begin{abstract}
Background: Brucellosis caused by Brucella abortus is one of the most important zoonoses in the world. Multiple-locus variable-number tandem repeat analysis (MLVA16) has been shown be a useful tool to epidemiological traceback studies in B. abortus infection. Thus, the present study aimed (i) to evaluate the genetic diversity of B. abortus isolates from a brucellosis outbreak, and (ii) to investigate the in vivo stability of the MLVA16 markers.

Results: Three-hundred and seventy-five clinical samples, including 275 vaginal swabs and 100 milk samples, were cultured from a brucellosis outbreak in a cattle herd, which adopted RB51 vaccination and test-and-slaughter policies. Thirty-seven B. abortus isolates were obtained, eight from milk and twenty-nine from post-partum/abortion vaginal swabs, which were submitted to biotyping and genotyping by MLVA16. Twelve B. abortus isolates obtained from vaginal swabs were identified as RB51. Twenty four isolates, seven obtained from milk samples and seventeen from vaginal swabs, were identified as $B$. abortus biovar 3 , while one isolate from vaginal swabs was identified as B. abortus biovar 1. Three distinct genotypes were observed during the brucellosis outbreak: RB observed in all isolates identified as RB51; W observed in all B. abortus biovar 3 isolates; and Z observed in the single B. abortus biovar 1 isolate. Epidemiological and molecular data show that the B. abortus biovar 1 genotype $Z$ strain is not related to the $B$. abortus biovar 3 genotype $W$ isolates, and represents a new introduction $B$. abortus during the outbreak.

Conclusions: The results of the present study on typing of multiple clinical B. abortus isolates from the same outbreak over a sixteen month period indicate the in vivo stability of MLVA16 markers, a low genetic diversity among B. abortus isolates and the usefulness of MLVA16 for epidemiological studies of bovine brucellosis.
\end{abstract}

Keywords: Genotyping, MLVA16 stability, Bovine brucellosis, B. abortus

\section{Background}

Brucellosis is a bacterial disease caused by microorganisms of the genus Brucella that affects different livestock and wild animal species, besides man [1]. Cattle are the preferred host of Brucella abortus and the economic importance attributed to bovine brucellosis is based on losses caused by abortions, stillbirths, weight loss, decreased milk production and the establishment

\footnotetext{
* Correspondence: alage@vet.ufmg.br

'Laboratório de Bacteriologia Aplicada, Departamento de Medicina

Veterinária Preventiva, Escola de Veterinária, Universidade Federal de Minas Gerais, Av. Antônio Carlos, 6627, Caixa Postal 567, 31270-901 Belo Horizonte, MG, Brazil

Full list of author information is available at the end of the article
}

of sanitary barriers to international trade of animals and their products [1].

Because direct and indirect losses triggered by $B$. abortus infection, the control and eradication of bovine brucellosis is an important goal of several countries where the disease is endemic, including Brazil that since 2001 has a national program on the control and eradication of brucellosis and tuberculosis (Programa Nacional de Controle e Erradicação da Brucelose e Tuberculose - PNCEBT) [2,3].

Typing of Brucella spp. by biovar determination and genotyping are important tools in a brucellosis control and eradication programs [4]. Indeed, molecular typing methods are commonly used to investigate epidemiological relationships among isolates and sources of

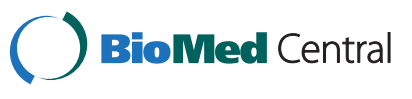


infection [5]. In this sense, the multiple locus variable number of tandem repeats (VNTR) analysis (MLVA) has proved to be an important tool in molecular epidemiology studies of brucellosis [6-11], in the characterization of new Brucella species [12] and in the evaluation of sources of human infection [13].

In MLVA context, the assessment of the genetic stability is one of the vital elements to guarantee the successful use of this typing method, since it could confirm its ability to differentiate between two independent strains, while depicting relationships among strains from the same source [14]. The genetic stability can be deduced by typing results of multiple isolates originating from the same strain or strains after numerous passages $[8,9,15,16]$. In in vitro evaluations, $B$. abortus vaccine and field strains have been shown to be stable by MLVA16 [9,15-17]. Regarding to in vivo stability of the MLVA16 markers, data based on $B$. abortus experimental infection showed only few changes in the hyper-variable loci [9]. Whereas, MLVA16 in vivo stability have not been evaluated under natural conditions.

Therefore, the aims of this study were $(i)$ to evaluate the genetic diversity of $B$. abortus isolates obtained from a single cattle brucellosis outbreak and (ii) to investigate the in vivo stability of the MLVA16 markers.

\section{Results}

\section{Serologic testing}

The incidence of brucellosis in the herd between May 2009 and January 2011 is shown in Figure 1. No positive animal was observed on three monthly tests after October 2011.

\section{Isolation and identification}

Thirty-seven isolates of $B$. abortus were obtained from 340 cows (375 samples) during the 16 months period of outbreak: eight from milk samples $(8 \%-8 / 100)$ and twenty-nine from post-partum vaginal swabs $(10.5 \%$ 29/275) (Table 1). Of the B. abortus isolates obtained from vaginal swabs samples eight were associated to abortion/ stillborn occurrence. Among animals that had vaginal swabs and milk samples collected (35 animals) three $B$. abortus isolates were obtained, all from vaginal swabs.

Based on phenotypic characteristics, twenty four strains were classified as B. abortus biovar 3 (seven from milk and seventeen from vaginal swabs) and thirteen as $B$. abortus biovar 1 (one from milk and twelve from vaginal swabs) (Table 1). All strains classified as B. abortus biovar 3 presented smooth colonial morphology. Among the thirteen B. abortus biovar 1 strains, twelve exhibited rough colonial morphology and growth on tryptose agar plates supplemented with rifampicin $(200 \mu \mathrm{g} / \mathrm{mL}$ ) (all from vaginal swabs), whereas one strain isolated from a milk sample was classified as smooth Brucella spp.

All strains were confirmed as belonging to the genus Brucella by genus-specific PCR [18], and as B. abortus by AMOS-enhanced PCR and Bruce-ladder multiplex PCR $[19,20]$. Moreover, the twelve isolates phenotypically classified as $B$. abortus biovar 1 rough strains were confirmed as RB51 vaccine strain by AMOS-enhanced PCR [19].

\section{MLVA16}

The set of genetic markers which comprises the MLVA16 was observed to be stable in vivo, even when evaluated

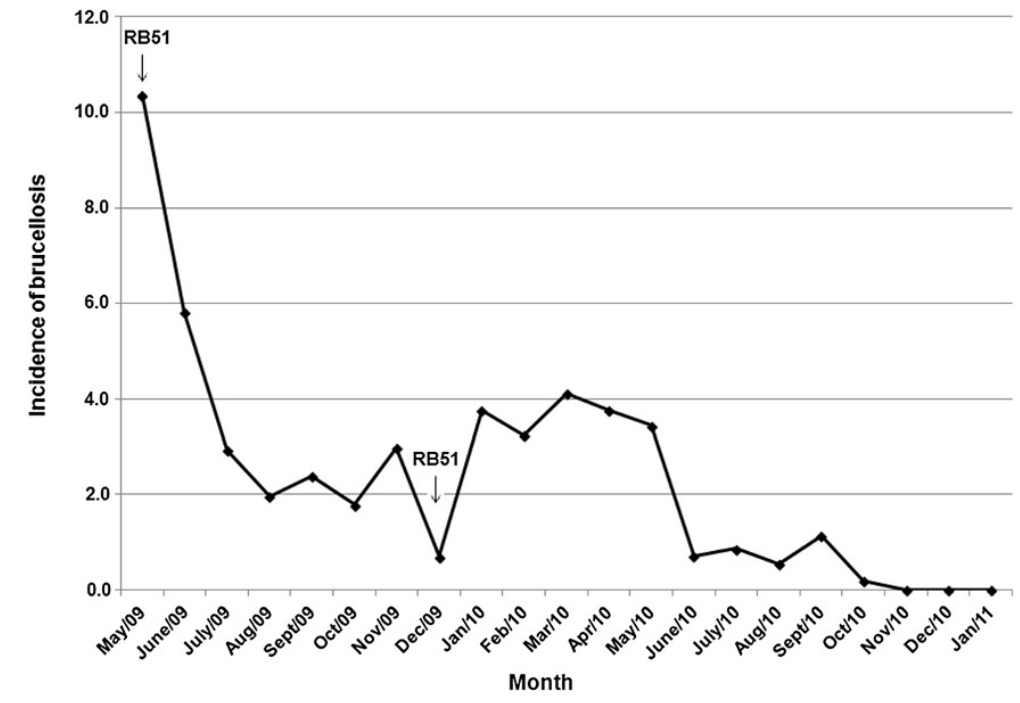

Figure 1 Monthly incidence of serologically positive cattle in a bovine brucellosis outbreak from May 2009 to January 2011, Minas Gerais, Brazil. All cattle older than 24 months were monthly tested for brucellosis [Rose Bengal Plate Agglutination Test (RBPAT) as a screening test and the Standard Tube Agglutination Test (STAT) and 2-Mercaptoethanol Test (2ME) as a confirmatory test]. Positive animals were culled until three consecutive negative herd results were obtained. The herd was vaccinated with RB51 on May 2009 and on December 2009 (RB51 vaccinations are highlighted with arrows). 
Table 1 Clinical signs, biotyping, molecular identification and genotyping of $B$. abortus isolates from a bovine brucellosis outbreak

\begin{tabular}{|c|c|c|c|c|c|}
\hline Strain & Clinical sample & Collection date & Biovar & Genotype $^{b}$ & Clinical signal \\
\hline 1414 & vaginal swab & 09/01/2009 & 3 & W & Abortion \\
\hline 2757 & vaginal swab & 09/01/2009 & 1 & RB & - \\
\hline 2985 & vaginal swab & 09/01/2009 & 3 & W & - \\
\hline 3144 & vaginal swab & $10 / 01 / 2009$ & 1 & RB & - \\
\hline 2575 & vaginal swab & 09/02/2009 & 3 & W & - \\
\hline 2558 & vaginal swab & 07/03/2009 & 1 & $\mathrm{RB}$ & - \\
\hline 2608 & vaginal swab & 08/03/2009 & 1 & RB & - \\
\hline 1379 & vaginal swab & 07/04/2009 & 1 & RB & - \\
\hline 3136 & vaginal swab & $10 / 05 / 2009$ & 1 & RB & - \\
\hline 2634 & vaginal swab & 10/07/2009 & 3 & W & Abortion \\
\hline 1365 & milk & 07/27/2009 & 3 & W & Stillbirth \\
\hline 2476 & milk & 07/27/2009 & 3 & W & - \\
\hline 2598 & milk & 07/27/2009 & 3 & W & Stillbirth \\
\hline 2683 & milk & 07/27/2009 & 3 & W & - \\
\hline 2785 & milk & 07/27/2009 & 3 & W & - \\
\hline 2965 & milk & 07/27/2009 & 3 & W & - \\
\hline 2980 & milk & 07/27/2009 & 3 & W & - \\
\hline 3159 & vaginal swab & 07/27/2009 & 1 & RB & - \\
\hline 2922 & vaginal swab & 08/18/2009 & 1 & RB & - \\
\hline 3169 & vaginal swab & 08/21/2009 & 1 & $\mathrm{RB}$ & - \\
\hline 2545 & vaginal swab & 09/19/2009 & 3 & W & Stillbirth \\
\hline 2595 & vaginal swab & 10/17/2009 & 3 & W & - \\
\hline 1198 & vaginal swab & 10/28/2009 & 3 & W & Abortion \\
\hline 1219 & vaginal swab & 10/28/2009 & 3 & W & Abortion \\
\hline 2251 & vaginal swab & 07/11/2009 & 3 & W & - \\
\hline 2496 & vaginal swab & 07/11/2009 & 3 & W & - \\
\hline 2700 & vaginal swab & 09/11/2009 & 3 & W & Abortion \\
\hline 2588 & vaginal swab & 01/28/2010 & 3 & W & - \\
\hline 3238 & vaginal swab & 05/03/2010 & 3 & W & Stillbirth \\
\hline 2726 & vaginal swab & 03/28/2010 & 1 & RB & - \\
\hline 3006 & vaginal swab & 05/04/2010 & 3 & W & - \\
\hline 2998 & vaginal swab & 04/15/2010 & 3 & W & - \\
\hline 3022 & vaginal swab & 04/27/2010 & 3 & W & - \\
\hline 3016 & vaginal swab & 04/30/2010 & 3 & W & - \\
\hline 2774 & vaginal swab & 02/06/2010 & $1^{a}$ & Z & - \\
\hline 2543 & vaginal swab & 03/11/2010 & 1 & RB & - \\
\hline 2850 & vaginal swab & 03/11/2010 & 1 & RB & - \\
\hline
\end{tabular}

${ }^{a}$ B. abortus biovar 1 field strain.

${ }^{\mathrm{b}}$ MLVA16 genotype.

from different clinical specimens over a 16 months outbreak. Analysis of the MLVA16 loci revealed three distinct genotypes among the $37 \mathrm{~B}$. abortus strains isolated during the brucellosis outbreak, herein these genotypic patterns were labeled $\mathrm{RB}, \mathrm{W}$ and $\mathrm{Z}$, for new genotypes the identification adopted was sequential in the same way used by Minharro et al. [11] (Table 1). The genotype RB was observed in all twelve strains identified as $B$. abortus RB51, which were all obtained from vaginal swab samples. The genotype $\mathrm{W}$ was observed in all twenty four isolates 
classified as B. abortus biovar 3 (seven from milk and seventeen from vaginal swabs), while genotypic profile $\mathrm{Z}$ was observed in only one strain, which was isolated from milk and identified as a smooth $B$. abortus biovar 1 field strain. This biovar 1 strain was isolated eleven months after confirmation of brucellosis in the herd on February/ 2010, being one of the last strains isolated, since clinical samples were collected until May/2010 (Table 1).

Patterns obtained in the sixteen VNTR loci are summarized in Table 2. Comparison of the results observed in the eight conserved loci included in panel 1 by Le Flèche et al. [6] with those available in the MLVA bank 2014 (http://mlva.u-psud.fr/brucella/) showed genotypes 27, 40 and 28 for the strains classified as MLVA16 genotypes $\mathrm{RB}, \mathrm{W}$ and $\mathrm{Z}$, respectively. Genotype $\mathrm{RB}$ was identical to the previously describe $[6,16]$ for $R B 51$ vaccine strain. The MLVA16 pattern for genotypes $\mathrm{W}$ and $\mathrm{Z}$ did not find correspondence with those deposited on MLVA bank 2014. In comparison with genotype $W$, the genotype $Z$ exhibited different alleles in the loci Bruce04, Bruce06, Bruce11, Bruce16, Bruce18 and Bruce30 (Table 2).

\section{Discussion}

Results from the present study on 37 B. abortus isolates from milk and vaginal swabs taken from 340 cows (375 samples) during a 16 months period showed the in vivo genetic stability of the MLVA16 markers. Molecular

Table 2 Allelic types of MLVA16 loci observed for B. abortus strains isolated from a bovine brucellosis outbreak

\begin{tabular}{lcc}
\hline Locus & Tandem repeat copy numbers & $\begin{array}{l}\text { Number } \\
\text { of anel }\end{array}$ \\
\cline { 2 - 3 } & Genotype W Genotype Z Genotype RB &
\end{tabular}

\begin{tabular}{llllll}
\hline Bruce06 & 3 & 4 & 4 & 2 & 1 \\
Bruce08 & 5 & 5 & 5 & 1 & 1 \\
Bruce11 & 3 & 4 & 4 & 2 & 1 \\
Bruce12 & 12 & 12 & 12 & 1 & 1 \\
Bruce42 & 2 & 2 & 2 & 1 & 1 \\
Bruce43 & 2 & 2 & 3 & 2 & 1 \\
Bruce45 & 3 & 3 & 3 & 1 & 1 \\
Bruce55 & 3 & 3 & 3 & 1 & 1 \\
Bruce18 & 7 & 6 & 6 & 2 & $2 \mathrm{~A}$ \\
Bruce19 & 42 & 42 & 42 & 1 & $2 \mathrm{~A}$ \\
Bruce21 & 8 & 8 & 8 & 1 & $2 \mathrm{~A}$ \\
Bruce04 & 5 & 3 & 3 & 2 & $2 \mathrm{~B}$ \\
Bruce07 & 4 & 4 & 7 & 2 & $2 \mathrm{~B}$ \\
Bruce09 & 3 & 3 & 3 & 1 & $2 \mathrm{~B}$ \\
Bruce16 & 3 & 5 & 3 & 2 & $2 \mathrm{~B}$ \\
Bruce30 & 3 & 6 & 5 & $2 \mathrm{~B}$ \\
\hline
\end{tabular}

typing methods are commonly used to investigate epidemiological relationships among isolates and sources of infection [5]. However, before being used for those purposes, PCR methods for molecular typing require careful in-house validation of typeability, reproducibility, repeatability, stability, discriminatory power and epidemiologic concordance [5,21]. The findings of this study, associated with previous data on the high discriminatory power and epidemiologic concordance of MLVA16, besides its good typeability and in vitro stability [6,7,9-11,13,15-17], corroborate the use of MLVA16 as suitable typing method for refining the understanding of the epidemiology of bovine brucellosis.

Our results showed a low genetic diversity and the existence of three different $B$. abortus strains within a focus of bovine brucellosis, the RB51 vaccine strain (genotype RB), recovered from animals that were twice vaccinated in the period, and two field strains (genotypes $\mathrm{W}$ and $\mathrm{Z}$ ).

In the present study no RB51 was isolated from the milk of any animal during the post-partum period (30-60) but only from vaginal swabs, although some cows have been vaccinated in the last third of pregnancy and a highly sensitive diagnostic strategy have been employed [22]. These results were corroborated by previous studies that also reported no recovery of B. abortus RB51 from any of the milk sample tested by conventional bacteriological methods of cows vaccinated during pregnancy or 30-60 days after delivery [23,24]. Regarding the presence of viable RB51 in postpartum vaginal secretion, it is important to consider that all animals from which RB51 were recovered after delivery were over 5 months of gestation by the time of revaccination with this strain and that no abortion was related to RB51 isolation (Table 1). Thus, it is likely that the RB51 booster had contributed to the recovery of the vaccine strain in postpartum period, since it has been observed that during transition period a depression in cell-mediated response occurs, which leads to a decrease of the resistance to disease or increase of the residual virulence of vaccines [25].

Other important finding of this study was the demonstration of viable $B$. abortus in milk from infected animals associated with the outbreak, corroborating the public health risk of the consumption of raw milk and unpasteurized dairy products [26]. The colonization of the mammary gland and associated lymph nodes by $B$. abortus with excretion of microorganisms in milk was already demonstrated [27]. In addition, it is important to emphasize that the methodologies used for bacterial culture and molecular identification were able to differentiate RB51 vaccine strain from $B$. abortus field strains.

Interestingly, field strains isolated from this brucellosis outbreak showed distinct genotypes and biotypes, 
suggesting that the outbreak had two different sources of infection. The majority of $B$. abortus isolates from the outbreak (24/25) were classified as B. abortus biovar 3 genotype $\mathrm{W}$, which remained the single cause of brucellosis in the herd for eleven months (from March 2009 to February 2010). This widely demonstrates that the introduction of this strain in the herd was responsible for the occurrence of the outbreak and consequently for the high abortion rate observed at the end of 2008. Furthermore, in February 2010, the introduction into the herd of another field strain, B. abortus biovar 1 genotype $\mathrm{Z}$, was observed. This genotype $\mathrm{Z}$ was confirmed by a twice repetition of MLVA16 genotyping assay that showed the same results. There are two possible explanations for the presence of this infected animal, negative to the conventional serological tests adopted in the herd: first, this heifer was congenitally and persistently infected without seroconversion [28], and second, the negative serological result from this infected heifer was a false negative result inherent to any diagnostic test. However, the diagnostic strategy employed was very sensitive [29], which tends to minimized false negative results. Since this second field strain was represented by just one isolate, it is very likely that the control policy adopted in the herd, which included test-and-removal procedures, has prevented the dissemination of this strain to other animals and consequently a new increase in the brucellosis prevalence levels into the herd.

Besides the differences in the classification of biovar, the differences observed between the genotypes of the field strains were very large and not limited to differences in the more variable loci (Bruce04, Bruce16, Bruce18 and Bruce30), but were also observed in conserved loci, such as Bruce06 and Bruce11 (Table 2). Therefore, the identification of the new source of infection in the herd was only possible due the use of MLVA16, otherwise the genotype $\mathrm{Z}$ strain would have been considered just another B. abortus isolate within the outbreak.

Epidemiological data of the herd also confirmed that the $B$ abortus biovar 1 genotype $\mathrm{Z}$ strain was a newly introduced strain in the farm, since the young heifer from which this strain was isolated was introduced in the herd shortly at the end of the outbreak (November/2009). In fact, it has been widely demonstrated that the purchase of infected animals is the main risk factor for the introduction of brucellosis in free herds [30]. Unfortunately, it was not possible to obtain more epidemiological data about the heifer from which the second B. abortus field strain was isolated, such as the brucellosis status of the herd of origin, which would have allowed a better understanding about the epidemiology of the genotype $\mathrm{Z}$ strain.

The MLVA16 panel 1 profiles of both B. abortus isolates, genotypes 28 and 40 by the MLVAbank, have already been previously observed in Minas Gerais State [11]. Moreover, the comparison between MLVA16 genotypes of B. abortus biovar 3 field strain (W) and those previously described by Minharro et al. [11] revealed differences restricted to hypervariable loci [panels $2 \mathrm{~A}$ (Bruce19) and 2B (Bruce04)], suggesting a possible epidemiological link between these strains, since all were isolated in the state of Minas Gerais and were also identified as biovar 3 . For the single field strain classified as genotype $\mathrm{Z}$, the comparison with MLVA16 patterns previously described by Minharro et al. [11] showed a genetic distance of one locus (Bruce19) from a B. abortus biovar 2 also isolated from Minas Gerais State.

In a brucellosis control and eradication program the use of an accurate surveillance and highly discriminatory typing method is essential to characterize an outbreak and determine the source of infection and the transmission routes. The present results on typing multiple $B$. abortus isolates from an outbreak originated from an outbreak in the same herd depicted the in vivo stability of the MLVA16 markers. The set of loci that comprise the MLVA16 demonstrated to be very stable, even when assessed over the time span of one year and four months, since the field strain mainly responsible by the outbreak (W) and the RB51 vaccine strain recovered from vaccinated animals showed unchanged MLVA16 profiles. These findings are extremely important because they definitely confirm the ability of the MLVA16 to establish correct epidemiological correlations, since, besides having a high discriminatory power, MLVA16 markers were also stable under natural selection pressure exerted by the host, during the sixteen months assessed. Thus, these results increase the confidence in the traceback established from the results of MLVA16 and further support this technique as the choice one for typing B. abortus.

Futhermore, the examination of in vitro stability of the B. abortus RB51 vaccine strain, B. abortus strain 2308 and $B$. abortus field isolates by serial passages in culture medium showed no change in MLVA16 profile $[9,16]$. Likewise, the analysis of $B$. abortus S19 vaccine strain from different batches of different manufacturers did not reveal significant differences in MLVA16 pattern [17]. Concerning the evaluation of in vivo genetic stability of MLVA16 loci, it has also been demonstrated that passage of B. abortus RB51 in cattle and of B. abortus 2308 in mouse did not lead to changes in any marker of MLVA16 [9]. Nevertheless, minor changes in VNTR pattern were observed in in vitro passages of B. abortus 544 and in genotyping of multiple $B$. abortus isolates from the same outbreak [9]. Her et al. [9] found different allelic profiles in seven of twenty-three herds in which more than one $B$. abortus isolates were obtained. Those different genotypes from same outbreak showed mutations only 
in the loci Bruce 30 and 43, which did not seem to affect the identification of a possible common origin of the strains [9]. However, our data showing the high in vivo stability of the MLVA16 loci have as main findings over previous data the large numbers of isolates (37) obtained from the same source, the long period of time assessed (16 months) and the typing of strains colonizing different sites (mammary gland or reproductive tract), and therefore under different selective environmental pressures.

\section{Conclusions}

The results of the present study on typing of multiple isolates from different clinical specimens originating from the same outbreak over a sixteen month period indicate the in vivo stability of the MLVA16 markers, a low genetic diversity among $B$. abortus isolates and the usefulness of MLVA16 for epidemiological studies of bovine brucellosis.

\section{Methods}

\section{Outbreak description}

The experiment was conducted during an outbreak of brucellosis in a cattle herd located in Matozinhos, Minas Gerais, Brazil. The herd was composed of 705 Holstein dairy cows, reared in an intensive system. All animals in the herd were vaccinated with S19 between 3 to 8 month of age and tested for brucellosis twice a year according to PNCEBT [3] [Rose Bengal Plate Agglutination Test (RBPAT) as a screening test and the Standard Tube Agglutination Test (STAT) and 2-Mercaptoethanol Test (2ME) as a confirmatory tests]. During 2008, several lots of heifers were acquired in order to increase the milk production of the herd. Prior to introduction into the herd, all heifers were serologically tested [3] and only lots with brucellosis-negative animals were acquired.

Suspicion of brucellosis in the herd started with an abnormal high abortion rate (15\%) observed by the end of 2008. Brucellosis was confirmed serologically on March 2009 , and a control program based on mass vaccination with RB51 and a test-and-slaughter policy was initiated. PNCEBT demands the compulsory S19 vaccination of female calves aged 3 to 8 month and recommends the voluntary RB51 vaccination of heifers older than 8 month and cows in B. abortus infected herds. All female animals over eight months of age were revaccinated with RB51, including pregnant heifers and cows. The herd was revaccinated with RB51 on two different occasions: the first in May 2009 and the second in December 2009. Moreover, all cattle older than 24 months were monthly tested for brucellosis (RBPAT as screening test and STAT and 2ME as a confirmatory test) and the positive animals were culled [3] until three consecutive negative herd results were obtained.
The experimental protocol was approved by Ethics Committee on Animal Experimentation of Universidade Federal de Minas Gerais (CETEA/UFMG - Protocol 139/10).

\section{Clinical samples}

Three-hundred and seventy-five clinical samples were collected from 340 cows between January 2009 and May 2010 during the brucellosis outbreak; those included 275 vaginal swabs and 100 milk samples. Of thirty-five animals were collected both, vaginal swabs and milk samples. Vaginal swabs were collected in Stuart medium from all cows immediately after abortion (twenty-two samples) or delivery, whereas milk samples were obtained from all cows that had 60 days or less of the last parturition or abortion at 57 days after the first RB51 vaccination $(07 / 27 / 2009)$. For each animal, $50 \mathrm{~mL}$ of milk was collected after discarding of the first jet (milk from the four quarter was mixed). Both clinical samples were stored at $-20^{\circ} \mathrm{C}$ until processing.

\section{Culture conditions}

Vaginal swabs were thawed and directly plated onto duplicate tryptose agar plates (Difco, USA) with antibiotics (Farrell's selective supplement) (Oxoid, UK) [31], and they were also inoculated in $10 \mathrm{~mL}$ of enrichment medium (tryptose broth supplemented with Farrell's selective supplement) [22]. Milk samples were thawed and centrifuged at $2500 \times g$, for 15 minutes. The intermediated phase was discarded and the supernatant was mixed with the pellet. Aliquots of $100 \mu \mathrm{L}$ of each mixture was immediately inoculated onto duplicate tryptose agar plates (Difco, USA) with antibiotics (Farrell's selective supplement) (Oxoid, UK) [31]. Another aliquot of $1 \mathrm{~mL}$ of each mixture was diluted in $9 \mathrm{~mL}$ of enrichment medium. The enrichment media inoculated with vaginal swabs or milk were incubated at $37^{\circ} \mathrm{C}$ for seven days in $5 \%$ of $\mathrm{CO}_{2}$ and then inoculated onto tryptose agar plates with antibiotics [22]. All plates were incubated in $5 \%$ of $\mathrm{CO}_{2}$ at $37^{\circ} \mathrm{C}$ for at least 14 days [31].

\section{Identification and biotyping of Brucella spp. isolates}

Brucella spp. solates were identified to genus based on colony morphology, positive tests for urease, catalase and nitrate reduction, and negative tests for motility and citrate utilization [31,32]. Classification into species and biovar was performed by $\mathrm{H}_{2} \mathrm{~S}$ production, agglutination with sera anti-A, anti-M, anti- $\mathrm{R}$ and acriflavin, growth in $\mathrm{CO}_{2}$ and $\mathrm{O}_{2}$ atmospheres and sensitivity to thionin $(20 \mu \mathrm{g} / \mathrm{mL}$ and $40 \mu \mathrm{g} / \mathrm{mL})$, basic fuchsin $(20 \mu \mathrm{g} / \mathrm{mL})$, and rifampicin $(200 \mu \mathrm{g} / \mathrm{mL})$ [31-33].

Suspected Brucella spp. colonies were also suspended in $100 \mu \mathrm{L}$ of Tris EDTA $(10 \mathrm{mM}$ Tris- $\mathrm{HCl}, 1 \mathrm{mM}$ EDTA, $\mathrm{pH}$ 8.0), inactivated at $85^{\circ} \mathrm{C}$ for 2 hours and subjected to genomic DNA extraction [34]. DNA quality and concentration were determined by spectrophotometry [35]. 
Polymerase chain reaction (PCR) for amplification of the gene $b c s p 31$ [18] and AMOS-enhanced PCR [19] were also used for identification of isolates [see Additional file 1: Table S1]. Since B. abortus biovar 3 strains are not identified by AMOS-enhanced PCR, these strains were also analyzed by Bruce-ladder multiplex PCR [20] to confirm their identification as $B$. abortus [see Additional file 1: Table S1].

Reference strains, used as control in different procedures, were: B. abortus biovar $1544=$ ATCC $23448^{\mathrm{T}} ;$ B. abortus biovar 2 ATCC 23449; B. abortus biovar 3 Tulya = ATCC 23450; B. abortus biovar 4 292 = ATCC 23451; B. abortus biovar $53196=$ ATCC 23452; B. abortus biovar $6870=$ ATCC 23453; B. abortus biovar 9 C68 = ATCC 23455; B. abortus biovar $1 \mathrm{~S} 19 ; B$. abortus biovar 1 RB51; $B$. melitensis biovar $116 \mathrm{M}=\mathrm{ATCC} 23456^{\mathrm{T}}$; B. ovis Reo 198; B. suis biovar 11330 = ATCC 23444; Escherichia coli $=$ ATCC 25922; E. coli B41; Listeria monocytogenes = ATCC 19115; Pseudomonas aeroginosa $=$ ATCC 27853; Salmonella enterica serovar Typhimurium = ATCC 14028; and Staphylococcus aureus = ATCC 29213.

\section{MLVA 16 genotyping}

DNA from each strain was genotyped by a subset of 16 tandem repeat loci (MLVA16) as previously described [6,7] [see Additional file 1: Table S1]. The method analyses 16 VNTR loci divided into three panels: panel 1 composed of eight minisatellites (Bruce06, Bruce08, Bruce11, Bruce12, Bruce42, Bruce43, Bruce 45 and Bruce55); panel 2A composed of three microsatellites (Bruce18, Bruce19 and Bruce21); and panel 2B with five microsatellites (Bruce04, Bruce07, Bruce09, Bruce16 and Bruce30) [6,7].

The amplified products were submitted to electrophoresis in $2 \%$ or $3 \%$ agarose gel, for the mini and microsatellites, respectively, in Tris-borate-EDTA $1 \mathrm{X}$ (TBE) buffer, stained with $0.5 \mathrm{mg} / \mathrm{mL}$ ethidium bromide, visualized under UV light, and photographed (ImageMaster VDS, Phamarcia Biotech, Sweden). DNA size markers 100 bp (100 bp DNA Ladder, New England Biolabs, USA) and 25 bp (25 bp DNA Step Ladder, Promega, USA) were used to estimate the tandem repeat unit length.

Each estimated band size was converted into number of repeat units for each locus, with aid of the software BioNumerics 5.1 (Applied Maths, Belgium), as described [6]. Clustering analysis was performed using the same software based on the category coefficient and the unweighted pair group method with arithmetic mean (UPGMA) algorithm [6].

\section{Additional file}

Additional file 1: Table S1. Primers used in the present study.

\section{Competing interests}

The authors declare that they have no competing interests.

\section{Authors' contributions}

EMSD participated in the design, data acquisition and analysis, and wrote the paper. JAS, TMA, RBP and JPSM participated in data acquisition and analysis. MBH and APL conceived the study, participated in design of the study, data interpretation and reviewed the manuscript. All authors read and approved the final manuscript.

\section{Acknowledgements}

This study was supported by Conselho Nacional de Desenvolvimento Científico e Tecnológico (CNPq), Fundação de Amparo à Pesquisa do Estado de Minas Gerais - (Fapemig) and Fundação de Ensino e Pesquisa em Medicina Veterinária e Zootecnia (FEPMVZ) Coordenação Preventiva. The authors are extremely grateful to R Vilela and JPP Oliveira for their essential technical assistance in this study. EMSD, JAS, TMA, RBP, JPSM, MBH and APL are indebted to the CNPq for the fellowships.

\section{Author details}

${ }^{1}$ Laboratório de Bacteriologia Aplicada, Departamento de Medicina Veterinária Preventiva, Escola de Veterinária, Universidade Federal de Minas Gerais, Av. Antônio Carlos, 6627, Caixa Postal 567, 31270-901 Belo Horizonte, MG, Brazil. ${ }^{2}$ Present address: Departamento de Medicina Veterinária Preventiva e Saúde Animal - VPS, Faculdade de Medicina Veterinária e Zootecnia da Universidade de São Paulo, Av. Prof. Dr. Orlando Marques de Paiva, 87 - Cidade Universitária, 05508-270 São Paulo, SP, Brazil.

Received: 29 January 2014 Accepted: 25 June 2014

Published: 11 July 2014

\section{References}

1. Corbel MJ, Elberg SS, Cosivi O: Brucellosis in humans and animals. Geneva: WHO Press: 2006.

2. Poester FP, Gonçalves VS, Lage AP: Brucellosis in Brazil. Vet Microbiol 2002, 90:55-62.

3. Brasil: Ministério da Agricultura, Pecuária e Abastecimento. Instrução Normativa no 6, de 08 de janeiro de 2004. Aprova o Regulamento Técnico do Programa Nacional de Controle e Erradicação da Brucelose e da Tuberculose Animal - PNCEBT. Brasília, DF: Diário Oficial da União; 2004.

4. Bricker BJ: PCR as a diagnostic tool for brucellosis. Vet Microbio/ 2002 90:435-446.

5. Struelens MJ: Molecular epidemiologic typing systems of bacterial pathogens: current issues and perpectives. Mem Inst Oswaldo Cruz 1998, 93:581-585.

6. Le Flèche $P$, Jacques I, Grayon M, Al Dahouk S, Bouchon P, Denoeud F, Nöckler K, Neubauer H, Guilloteau LA, Vergnaud G: Evaluation and selection of tandem repeat loci for a Brucella MLVA typing assay. BMC Microbiol 2006, 6:9.

7. Al Dahouk S, Flèche PL, Nöckler K, Jacques I, Grayon M, Scholz HC, Tomaso $H$, Vergnaud G, Neubauer H: Evaluation of Brucella MLVA typing for human brucellosis. J Microbiol Methods 2007, 69:137-145.

8. García-Yoldi D, Le Fleche P, Marín CM, De Miguel MJ, Muñoz PM, Vergnaud G, López-Goñi I: Assessment of genetic stablility of Brucella melitensis Rev 1 vaccine strain by multiple-locus variable number tandem repeat analysis. Vaccine 2007, 25:2858-2862.

9. Her M, Kang SI, Cho DH, Cho YS, Hwang IY, Heo YR, Jung SC, Yoo HS: Application and evaluation of the MLVA typing assay for the Brucella abortus strains isolated in Korea. BMC Microbiol 2009, 9:230.

10. Álvarez J, Sáez JL, García N, Serrat C, Pérez-Sancho M, González S, Ortega MJ, Gou J, Carbajo L, Garrido F, Goyache J, Domínguez L: Management of an outbreak of brucellosis due to B. melitensis in dairy cattle in Spain. Res Vet Sci 2011, 90:208-211.

11. Minharro S, Mol JP, Dorneles EMS, Barbosa RP, Neubauer H, Melzer F, Poester FP, Dasso MG, Pinheiro ES, Soares Filho PM, Santos RL, Heinemann MB, Lage AP: Biotyping and genotyping (MLVA16) of Brucella abortus isolated from cattle in Brazil, 1977 to 2008. PLoS One 2013, 8:12.

12. Scholz HC, Hubalek Z, Sedlácek I, Vergnaud G, Tomaso H, Al Dahouk S, Melzer F, Kämpfer P, Neubauer H, Cloeckaert A, Maquart M, Zygmunt MS, Whatmore AM, Falsen E, Bahn P, Göllner C, Pfeffer M, Huber B, Busse HJ, Nöckler K: Brucella microti sp. nov., isolated from the commom vole Microtus arvalis. Int J Syst Evol Microbiol 2008, 58:375-382. 
13. Marianelli C, Petrucca A, Pasquali P, Ciuchini F, Papadoulou S, Cipriani P: Use of MLVA-16 typing to trace the source of a laboratory-acquired Brucella infection. J Hosp Infect 2008, 68:274-627.

14. Hunter PR: Reproducibility and indices of discriminatory power of microbial typing methods. J Clin Microbiol 1990, 28:1903-1905.

15. Whatmore AM, Shankster SJ, Perrett LL, Murphy TJ, Brew SD, Thirlwall RE, Cutler SJ, MacMillan AP: Identification and characterization of variable-number tandem-repeat markers for typing of Brucella spp. J Clin Microbiol 2006, 44:1982-1993.

16. Dorneles ESM, Faria APP, Pauletti RB, Santana JA, Caldeira GAV, Heinemann MB, Titze-de-Almeida R, Lage AP: Genetic stability of Brucella abortus S19 and RB51 vaccine strains by multiple locus variable number tandem repeat analysis (MLVA16). Vaccine 2013, 31:4856-4859.

17. Miranda KL, Poester FP, Minharro S, Dorneles EM, Stynen AP, Lage AP: Evaluation of Brucella abortus S19 vaccines commercialized in Brazil: immunogenicity, residual virulence and MLVA15 genotyping. Vaccine 2013, 31:3014-3018

18. Baily GG, Krahn JB, Drasar BS, Stocker NG: Detection of Brucella melitensis and Brucella abortus by DNA amplification. J Trop Med Hyg 1992, 95:271-275.

19. Bricker B, Halling S: Enhancement of the Brucella AMOS PCR assay for differentiation of Brucella abortus vaccine strains S19 and RB51. J Clin Microbiol 1995, 33:1640-1642.

20. Lòpez-Goñi I, García-Yoldi D, Marín CM, De Miguel MJ, Muñoz PM, Blasco JM, Jacques I, Grayon M, Cloeckaert A, Ferreira AC, Cardoso R, Corrêa De Sá MI, Walravens K, Albert D, Garin-Bastuji B: Evaluation of a multiplex PCR Assay (Bruce-Ladder) for molecular typing all Brucella species, including the vaccine strains. J Clin Microbiol 2008, 46:3484-3487.

21. Struelens MJ: Molecular typing: a key tool for the surveillance and control of nosocomial infection. Curr Opin Infect Dis 2002, 15:383-385.

22. Minharro S: Isolamento, Tipificação e Genotipagem de Brucella abortus isoladas de bovinos no Brasil. PhD Thesis. Universidade Federal de Minas Gerais, Escola de Veterinária; 2009.

23. Samartino LE, Fort M, Gregoret R, Schurig GG: Use of Brucella abortus vaccine strain RB51 in pregnant cows after calfhood vaccination with strain 19 in Argentina. Prev Vet Med 2000, 45:193-199.

24. Miranda KL: Evaluation of Brucellosis Vaccines in Brazil. Universidade Federal de Minas Gerais, Escola de Veterinária: PhD Thesis; 2009.

25. Weinberg ED: Pregnancy-associated depression of cell-mediated immunity. Rev Infect Dis 1984, 6:814-831.

26. Pappas G, Panagopoulou P, Christou L, Akritidis N: Brucella as a biological weapon. Cell Mol Life Sci 2006, 63:2229-2236.

27. Xavier MN, Paixão TA, Poester FP, Lage AP, Santos RL: Pathological, immunohistochemical and bacteriological study of tissues and milk of cows and fetuses experimentally infected with Brucella abortus. J Comp Pathol 2009, 140:149-157.

28. Crawford RP, Huber JD, Adama BS: Epidemiology and Surveillance. In Animal Brucellosis. Edited by Nielsen K, Duncan JR. Boca Raton: CRC Press; 1990:131-152.

29. Nielsen K: Diagnosis of brucellosis by serology. Vet Microbiol 2002, 90:447-459.

30. Nicoletti P: The epidemiology of bovine brucellosis. Adv Vet Sci Comp Med 1980, 24:69-98.

31. Alton $\mathrm{GG}$, Jones $\mathrm{LM}$, Angus RD, Verger JM: Techniques for the brucellosis laboratory. Paris: INRA; 1988

32. MacFaddin JF: Pruebas bioquímicas para la identificacion de bactérias de importância clinica. Buenos Aires: Panamericana; 1980

33. Miranda KL, Dorneles EMS, Poester FP, Soares-Filho PM, Barbosa RP, Lage AP: Different resistance patterns of reference and field strains of Brucella abortus. Braz JMicrobiol 2013. in press.

34. Pitcher DG, Saunders NA, Owern RJ: Rapid extraction of bacterial genomic DNA with guanidium thyocianate. Lett App Microbiol 1989, 8:151-156.

35. Sambrook J, Russel D: Molecular cloning: a laboratory manual. Plymouth: CSHL Press; 2001

doi:10.1186/1471-2180-14-186

Cite this article as: Dorneles et al: Genetic stability of Brucella abortus isolates from an outbreak by multiple-locus variable-number tandem repeat analysis (MLVA16). BMC Microbiology 2014 14:186.

\section{Submit your next manuscript to BioMed Central and take full advantage of:}

- Convenient online submission

- Thorough peer review

- No space constraints or color figure charges

- Immediate publication on acceptance

- Inclusion in PubMed, CAS, Scopus and Google Scholar

- Research which is freely available for redistribution 